\title{
AÇÃo DiRETA DE INCONSTITUCIONALIDADE 5.996 AMAZONAS
}

RELATOR

REQTE.(S)

ADV.(A/s)

INTDO.(A/s)

ADV.(A/s)

Am. CuRiae.

ADV.(A/s)

ADV.(A/s)
: Min. AleXANDRE DeMoraes

: AsSOC BRAsil DA IND HigIENE PESSOAl PeRF E COSMETICOS

: Heloisa BARRoso Uelze Bloisi e Outro(A/S)

: MESA DiRETORA DA AsSEMbleia LegISLATIVA DO ESTADO DO AMAZONAS

: SEM REPRESENTAÇÃO NOS AUTOS

: HUMANE SOCIETY INTERNATIONAL - HSI

: GUSTAVO TEIXEIRA RAMOS

: MARIANA PRANDINI FRAGAASSIS

EMENTA: CONSTITUCIONAL. FEDERALISMO E RESPEITO ÀS REGRAS DE DISTRIBUIÇÃO DE COMPETÊNCIA. LEI ESTADUAL 289/2015 DO ESTADO DO AMAZONAS. PROIBIÇÃO DO USO DE ANIMAIS PARA O DESENVOLVIMENTO, EXPERIMENTOS E TESTES DE PRODUTOS COSMÉTICOS, DE HIGIENE PESSOAL, PERFUMES E SEUS COMPONENTES. COMPETÊNCIA LEGISLATIVA CONCORRENTE DO ESTADO EM MATÉRIA DE PROTEÇÃO AMBIENTAL (ART. 24, VI, CF). NORMA ESTADUAL AMBIENTAL MAIS PROTETIVA, SE COMPARADA COM A LEGISLAÇÃO FEDERAL SOBRE A MATÉRIA. INCONSTITUCIONALIDADE FORMAL. NÃO OCORRÊNCIA. PRECEDENTES. IMPROCEDÊNCIA DA AÇÃO.

1. As regras de distribuição de competências legislativas são alicerces do federalismo e consagram a fórmula de divisão de centros de poder em um Estado de Direito. Princípio da predominância do interesse.

2. A Constituição Federal de 1988, presumindo de forma absoluta para algumas matérias a presença do princípio da predominância do interesse, estabeleceu, a priori, diversas competências para cada um dos entes federativos - União, Estados-Membros, Distrito Federal e Municípios - e, a partir dessas opções, pode ora acentuar maior centralização de poder, principalmente na própria União (CF, art. 22), ora permitir uma maior descentralização nos Estados-Membros e nos 


\section{ADI 5996 / AM}

Municípios (CF, arts. 24 e 30, inciso I).

3. A Lei 289/2015 do Estado do Amazonas, ao proibir a utilização de animais para desenvolvimento, experimentos e testes de produtos cosméticos, de higiene pessoal, perfumes e seus componentes, não invade a competência da União para legislar sobre normas gerais em relação à proteção da fauna. Competência legislativa concorrente dos Estados (art. 24, VI, da CF).

4. A sobreposição de opções políticas por graus variáveis de proteção ambiental constitui circunstância própria do estabelecimento de competência concorrente sobre a matéria. Em linha de princípio, admitese que os Estados editem normas mais protetivas ao meio ambiente, com fundamento em suas peculiaridades regionais e na preponderância de seu interesse, conforme o caso. Precedentes.

5. Ação Direta de Inconstitucionalidade conhecida e julgada improcedente.

\section{A C Ó R D Ã O}

Vistos, relatados e discutidos estes autos, os Ministros do Supremo Tribunal Federal, em Sessão Virtual do Plenário, sob a Presidência do Senhor Ministro DIAS TOFFOLI, em conformidade com a certidão de julgamento, por unanimidade, acordam em julgar improcedente o pedido formulado na ação direta, nos termos do voto do Relator. Não participou deste julgamento, por motivo de licença médica, o Ministro CELSO DE MELLO.

Brasília, 15 de abril de 2020.

\section{Ministro AleXandre De Moraes}

Relator 


\section{AÇÃo DiRETA DE INCONSTITUCIONALIDADE 5.996 AMAZONAS}

RELATOR

REQTE.(S)

ADV.(A/s)

INTDO.(A/s)

ADV.(A/s)

AM. CURIAE.

ADV.(A/s)

ADV.(A/s)
: Min. Alexandre deMoraes

: AsSOc BRAsil Da Ind Higiene Pessoal Perf E COSMETICOS

: Heloisa BARRoso UELZE Bloisi e OUtro(A/S)

: Mesa Diretora da AsSembleia Legislativa

DO ESTADO DO AMAZONAS

: SEM REPRESENTAÇÃO NOS AUTOS

: HUMANE SOCIETY INTERNATIONAL - HSI

: GUSTAVO TEIXEIRA RAMOS

: MARIANA PRANDINI FRAGA ASSIS

\section{R E L AT Ó R I O}

O Senhor Ministro AleXANDRE De Moraes (Relator): Trata-se de Ação Direta de Inconstitucionalidade, com pedido de medida cautelar, proposta pela Associação Brasileira da Indústria de Higiene Pessoal, Perfumaria e Cosméticos - ABIHPEC para impugnar a validade constitucional da Lei Estadual 289/2015 do Estado do Amazonas, que proibiu "a utilização de animais para desenvolvimento, experimentos e testes de produtos cosméticos, de higiene pessoal, perfumes e seus componentes" naquele Estado.

Eis o teor da lei impugnada:

"Art. 1. . Fica proibida, no Estado do Amazonas, a utilização de animais para desenvolvimento, experimentos e testes de produtos cosméticos, de higiene pessoal, perfumes e seus componentes, sem prejuízo do disposto em legislação Municipal, Estadual ou Federal.

Art. 2. Para os fins dos dispositivos constantes no artigo anterior, consideram-se produtos cosméticos, de higiene pessoal, perfumes as preparações constituídas por substâncias naturais ou sintéticas, de uso externo nas diversas partes do corpo humano, pele, sistema capilar, unhas, lábios, órgãos genitais externos, dentes e membranas mucosas da cavidade oral, com o objetivo exclusivo ou principal de limpá-los, 


\section{ADI 5996 / AM}

perfumá-los, alterar sua aparência e ou alterar odores corporais e ou protegê-los ou mantê-los em bom estado.

Parágrafo único. São exemplos destes produtos, entre outros:

I - cremes, emulsões, loções, géis e óleos para a pele (mãos, rosto, pés etc.);

II - máscaras de beleza (com exclusão dos produtos de descamação superficial da pele por via química);

III - bases (líquidas, pastas, pós);

IV - pós para maquiagem, pós para aplicação após o banho, pós para a higiene corporal etc;

V - sabonetes, sabonetes desodorizantes etc.;

VI - perfumes, águas de toilette e água de colônia;

VII - preparações para banhos e duches (sais, espumas, óleos, géis etc.);

VIII - depilatórios;

IX - desodorizantes e antitranspirantes;

$X$ - produtos de tratamentos capilares;

XI - tintas capilares e desodorizantes;

XII - produtos para ondulação, desfrisagem e fixação;

XIII - produtos de lavagem (loções, pós, xampus);

XIV - produtos de manutenção do cabelo (loções, cremes, óleos);

XV - produtos de penteados (loções, lacas, brilhantinas);

XVI - produtos para a barba (sabões, espumas, loções etc.);

XVII - produtos de maquiagem e limpeza da cara e dos olhos;

XVIII - produtos a serem aplicados nos lábios.

Art. 3. ${ }^{\circ}$ As instituições, estabelecimentos de pesquisa e os profissionais que descumprirem as disposições constantes desta Lei serão punidos progressivamente com o pagamento de multa e as seguintes sanções:

I - à instituição:

a) multa no valor de 50.000 UFEAM, por animal;

b) dobra do valor da multa na reincidência;

c) suspensão temporária do alvará de funcionamento; 


\section{ADI 5996 / AM}

d) suspensão definitiva do alvará de funcionamento;

II - ao profissional:

a) multa no valor de 2.000 UFEAM;

b) dobra do valor da multa a cada reincidência.

Art. 4. ${ }^{\text {o }}$ São passíveis de punição as pessoas físicas, inclusive detentoras de função pública, civil ou militar, bem como toda instituição ou estabelecimento de ensino, organização social ou pessoa jurídica, com ou sem fins lucrativos, de caráter público ou privado, que intentarem contra o que dispõe esta Lei ou se omitirem no dever legal de fazer cumprir os ditames desta norma.

Art. $5^{\mathrm{o}} \mathrm{O}$ Poder Público fica autorizado a reverter os valores recolhidos em função das multas previstas por esta Lei para:

I - custeio das ações, publicações e conscientização da população sobre guarda responsável e direitos dos animais;

II - instituições, abrigos ou santuários de animais;

III - programas estaduais de controle populacional através da esterilização cirúrgica de animais, bem como programas que visem à proteção e ao bem-estar dos animais.

Art. 6. ${ }^{\circ}$ A fiscalização dos dispositivos constantes desta Lei e a aplicação das multas decorrentes da infração ficarão a cargo dos órgãos competentes da Administração Pública Estadual.

Art. 7. O Poder Executivo regulamentará a presente Lei. Art. 8. ․ Esta Lei entra em vigor na data de sua publicação."

A requerente afirma que a norma questionada viola as regras de competência dispostas no art. 24, VI e $\$ \S 1^{\circ}$ a $4^{\circ}$, da Constituição Federal, uma vez que o Estado do Amazonas teria invadido campo legislativo reservado à União para legislar sobre fauna, conservação da natureza e proteção do meio ambiente.

Sustenta a inconstitucionalidade formal da lei ao argumento de que a União, por meio da Lei 11.794/2008, "não somente permite a realização de testes em animais, mas também estabelece as normas gerais que disciplinam o tema". Assim, afirma que a lei federal estabeleceu os procedimentos para 


\section{ADI 5996 / AM}

uso científico de animais, de modo que a norma impugnada não poderia proibir essa utilização no que diz respeito ao "desenvolvimento, experimento e teste de produtos cosméticos, higiene pessoal, perfumes, e seus componentes".

Além disso, a requerente sustenta que a manutenção da norma impugnada no ordenamento jurídico ensejaria uma situação de insegurança jurídica, pois a "utilização de animais para desenvolvimento, experimento e teste de produtos cosméticos, higiene pessoal, perfumes e limpeza é permitida em alguns Estados e em outros não".

Com isso, requer a suspensão cautelar dos efeitos da lei e, ao final, pugna pela procedência do pedido, para declaração da inconstitucionalidade formal da Lei 289/2015 do Estado do Amazonas.

A ação foi processada segundo o rito do art. 12 da Lei 9.868/1999.

A Assembleia Legislativa do Estado do Amazonas prestou informações. Alega, em preliminar, (a) inexistência de pertinência temática, ao fundamento de que não haveria correspondência entre o objeto da ação e o estatuto social da requerente; e (b) eventual ofensa ao texto constitucional seria de forma reflexa, pois a verificação de inconstitucionalidade demandaria prévio exame da Lei 11.794/2008. No mérito, defende a constitucionalidade da norma, sustentando, em síntese, a ausência de usurpação da competência da União para legislar sobre a matéria, e que a lei impugnada não conflita com as normas gerais contidas na Lei 11.794/2008. Ao final, pugna pela improcedência da ação.

O Governador do Estado do Amazonas não apresentou suas informações em prazo legal.

A Advogada-Geral da União se manifestou pela improcedência do pedido, consignando que a Constituição Federal, nos termos do art. 225, § 1 o, inciso VII, "estabelece que a efetividade do direito ao meio ambiente ecologicamente equilibrado está conectada ao explícito dever atribuído ao Poder Público de proteger a fauna, restando vedada qualquer prática que coloque em risco sua função ecológica, provoque a extinção de espécies ou submeta animais a crueldade".

Assim, observa que a União, no exercício de sua competência, editou 


\section{ADI 5996 / AM}

a Lei 11.794/2008, segundo a qual "estabeleceu regime jurídico para a criação e a utilização de animais em atividades de ensino e pesquisa científica em todo o território nacional", de modo que a lei impugnada estaria na conformidade das diretrizes gerais. Nesse ponto, destaca que o modelo de proteção escolhido pela lei estadual, apesar de mais restritivo, não impôs uma limitação arbitrária.

Aberta vista à Procuradoria-Geral da República, não foi apresentada manifestação nos autos.

A Humane Society International (HSI) foi admitida no processo na qualidade de amicus curiae.

É o relatório. 


\section{AÇÃo DireTA DE INCONSTITUCIONALIDADE 5.996 AMAZONAS}

\section{O T O}

\section{O Senhor Ministro Alexandre de Moraes (Relator):}

Inicialmente, cumprimento os eminentes advogados Bruno Corrêa Burini e Gustavo Teixeira Ramos pelas sustentações orais enviadas por meio eletrônico em nome da requerente, Associação Brasileira da Indústria de Higiene Pessoal, Perfumaria e Cosméticos - ABIHPEC, e do amicus curiae Humane Society International - HSI, respectivamente.

Trata-se de Ação Direta de Inconstitucionalidade ajuizada pela Associação Brasileira da Indústria de Higiene Pessoal, Perfumaria e Cosméticos - ABIHPEC, em face da Lei Estadual 289/2015, que dispõe sobre a proibição da "utilização de animais para desenvolvimento, experimentos e testes de produtos cosméticos, de higiene pessoal, perfumes e seus componentes no Estado do Amazonas".

Em síntese, a requerente sustenta que a norma teria usurpado competência da União para legislar sobre normas gerais no que diz respeito à proteção da fauna (art. 24, VI, CF), bem como teria extrapolado a competência legislativa suplementar dos Estados, disposta nos $\S \S 1^{\underline{0}}$ a $4^{\mathrm{o}}$ do art. 24 da Constituição Federal.

Inicialmente, compete analisar as preliminares suscitadas pela Assembleia Legislativa do Estado do Amazonas (doc. 18), quais sejam, ausência de pertinência temática e ofensa reflexa ao texto constitucional.

A Constituição de 1988, alterando uma tradição em nosso direito constitucional, que a reservava somente ao Procurador-Geral da República, ampliou a legitimidade para propositura da ação direta de inconstitucionalidade, transformando-a em legitimação concorrente. Para alguns dos legitimados do art. 103 da Constituição Federal, porém, esta CORTE exige a presença da chamada pertinência temática, definida como o requisito objetivo da relação de pertinência entre a defesa do interesse específico do legitimado e o objeto da própria ação.

As associações de classe, embora constem do art. 103, IX, da CF, não 


\section{ADI 5996 / AM}

são legitimadas universais para a propositura das ações do controle concentrado de constitucionalidade, incumbindo-lhes a demonstração da pertinência temática, conforme pacificado no SUPREMO TRIBUNAL FEDERAL (ADI 4.722 AgR, Rel. Min. DIAS TOFFOLI, Pleno, DJe de 15/2/2017; ADI 2.747, Rel. Min. MARCO AURÉLIO, Pleno, DJ de 17/8/2007; ADI-MC-AgR 1.507, Rel. Min. CARLOS VELLOSO, Pleno, DJ de 22/9/1995).

Na hipótese dos autos, o art. $3^{\mathbf{o}}$ do Estatuto Social da associação autora diz o seguinte (doc. 7):

“Art. 3ำ - A finalidade precípua da Associação consiste em congregar, a nível nacional, as indústrias do setor de higiene pessoal, perfumaria e cosméticos, promovendo e defendendo seus legítimos interesses, com vistas ao desenvolvimento do segmento econômico que representam."

O conteúdo da norma impugnada, por sua vez, se refere à proibição de desenvolvimento, experimentos e testes, em animais, de produtos cosméticos, de higiene pessoal, de perfumes e seus componentes, dentro do Estado do Amazonas. Assim, verifico que a associação autora demonstrou, de forma adequada e suficiente, a existência desse vínculo de pertinência temática em relação ao objeto da presente ação direta.

Além disso, tampouco merece acolhimento a alegada necessidade de confronto prévio entre normas infraconstitucionais. Isso porque a requerente aponta, com objetividade e de forma fundamentada, os dispositivos constitucionais que reputa violados, referentes à competência legislativa concorrente estabelecida na Carta Magna. O conflito de lei estadual com a Lei Federal 11.794/2008 foi mencionado subsidiariamente, apenas para demonstrar que a União já teria legislado sobre a matéria.

No caso em análise, a eventual ofensa à Constituição Federal ocorreria de maneira direta, uma vez que a incursão de um ente da Federação no campo legislativo constitucionalmente outorgado a outro ente é razão suficiente para, por si só, fundamentar o pedido de declaração de inconstitucionalidade de lei por vício formal orgânico. 


\section{ADI 5996 / AM}

Nesse sentido: ADI 4.955, Rel. Min. DIAS TOFFOLI, Tribunal Pleno, DJe de 17/11/2014; ADI 3.645, Rel. Min. ELLEN GRACIE, Tribunal Pleno, DJ de 1\%/9/2006; ADI 2535 MC, Rel. Min. SEPÚLVEDA PERTENCE, Tribunal Pleno, DJ de 21/11/2003. Dessa forma, rejeito as preliminares.

Quanto ao mérito, cumpre verificar se o Estado do Amazonas poderia, legitimamente, à luz das normas de distribuição de competências legislativas estatuídas na Constituição Federal, disciplinar o conteúdo posto na norma impugnada.

Antes, é importante deixar registrado que o meio ambiente, como um todo, obteve especial atenção por parte do legislador constituinte, que impôs ao Poder Público e à coletividade o dever de defendê-lo e preserválo para as presentes e futuras gerações (art. 225, caput, da CF). Para dar efetividade ao direito ao meio ambiente ecologicamente equilibrado, também assegurado em sede constitucional, ficou o Poder Público incumbido, entre outros deveres, de proteger a fauna e a flora, sendo vedadas, na forma da lei, as práticas que coloquem em risco sua função ecológica, provoquem a extinção de espécies ou submetam os animais a crueldade (art. 225, § 1으, VII, da CF).

A Constituição Federal de 1988 consagrou como obrigação do Poder Público a defesa, preservação e garantia de efetividade do direito fundamental ao meio ambiente ecologicamente equilibrado, bem de uso comum do povo e essencial à sadia qualidade de vida. Conforme sempre defendi, no caput do art. 225, o texto constitucional afirma ser o meio ambiente bem de uso comum do povo, suscitando a utilização de todos os meios legislativos, administrativos e judiciais necessários à sua efetiva proteção, que possui um regime jurídico especial que exorbita o Direito Comum. O meio ambiente deve, portanto, ser considerado patrimônio comum de toda a humanidade para garantia de sua integral proteção, especialmente em relação às gerações futuras, direcionando todas as condutas do Poder Público estatal no sentido de integral proteção legislativa interna e adesão aos pactos e tratados internacionais protetivos desse direito humano fundamental de $3^{\underline{a}}$ geração, para evitar prejuízo da coletividade em face de uma afetação de certo bem a uma finalidade 


\section{ADI 5996 / AM}

individual.

Dada a relevância da matéria, o legislador constituinte distribuiu entre todos os entes federativos as competências materiais e legislativas em matéria ambiental, inclusive com a expressa referência à proteção da fauna, reservando ao ente central (União) o protagonismo necessário para a edição de normas de interesse geral e, aos demais entes, a possibilidade de suplementarem essa legislação geral.

É o que se depreende da leitura dos arts. 23 e 24 da Constituição Federal, abaixo destacados:

“Art. 23. É competência comum da União, dos Estados, do Distrito Federal e dos Municípios:

(...)

VII - preservar as florestas, a fauna e a flora;

(...)

Art. 24. Compete à União, aos Estados e ao Distrito Federal legislar concorrentemente sobre:

(...)

VI - florestas, caça, pesca, fauna, conservação da natureza, defesa do solo e dos recursos naturais, proteção do meio ambiente e controle da poluição;

(...)

$\S 1^{\mathrm{o}}$ No âmbito da legislação concorrente, a competência da União limitar-se-á a estabelecer normas gerais.

$\S 2^{\underline{o}}$ A competência da União para legislar sobre normas gerais não exclui a competência suplementar dos Estados. "

No âmbito da União, vige a Lei Federal 11.794/2008, que regulamenta o inciso VII do $\S 1^{\circ}$ do art. 225 da Constituição Federal e estabelece os procedimentos para o uso científico de animais, dispondo o seguinte (grifos aditados):

\section{“Lei Federal 11.794/2008}

Art. $1^{\frac{0}{}}$ A criação e a utilização de animais em atividades 


\section{ADI 5996 / AM}

de ensino e pesquisa científica, em todo o território nacional, obedece aos critérios estabelecidos nesta Lei.

$\S 1^{o}$ A utilização de animais em atividades educacionais fica restrita a:

I - estabelecimentos de ensino superior;

II - estabelecimentos de educação profissional técnica de nível médio da área biomédica.

$\S 2^{\text {o }}$ São consideradas como atividades de pesquisa científica todas aquelas relacionadas com ciência básica, ciência aplicada, desenvolvimento tecnológico, produção e controle da qualidade de drogas, medicamentos, alimentos, imunobiológicos, instrumentos, ou quaisquer outros testados em animais, conforme definido em regulamento próprio.

$\S 3^{0}$ Não são consideradas como atividades de pesquisa as práticas zootécnicas relacionadas à agropecuária."

No tocante às condições de criação e uso de animais para ensino e pesquisas científicas, a Lei 11.794/2008 assim estabelece:

\section{“Lei Federal 11.794/2008}

Art. 14. O animal só poderá ser submetido às intervenções recomendadas nos protocolos dos experimentos que constituem a pesquisa ou programa de aprendizado quando, antes, durante e após o experimento, receber cuidados especiais, conforme estabelecido pelo CONCEA.

$\S 1^{\mathrm{o}} \mathrm{O}$ animal será submetido a eutanásia, sob estrita obediência às prescrições pertinentes a cada espécie, conforme as diretrizes do Ministério da Ciência e Tecnologia, sempre que, encerrado o experimento ou em qualquer de suas fases, for tecnicamente recomendado aquele procedimento ou quando ocorrer intenso sofrimento.

$\S 2^{\underline{o}}$ Excepcionalmente, quando os animais utilizados em experiências ou demonstrações não forem submetidos a eutanásia, poderão sair do biotério após a intervenção, ouvida a respectiva CEUA quanto aos critérios vigentes de segurança, desde que destinados a pessoas idôneas ou entidades 


\section{ADI 5996 / AM}

protetoras de animais devidamente legalizadas, que por eles queiram responsabilizar-se.

$\S 3^{\text {o }}$ Sempre que possível, as práticas de ensino deverão ser fotografadas, filmadas ou gravadas, de forma a permitir sua reprodução para ilustração de práticas futuras, evitando-se a repetição desnecessária de procedimentos didáticos com animais.

$\S 4^{\mathrm{o}} \mathrm{O}$ número de animais a serem utilizados para a execução de um projeto e o tempo de duração de cada experimento será o mínimo indispensável para produzir o resultado conclusivo, poupando-se, ao máximo, o animal de sofrimento.

$\S 5^{0}$ Experimentos que possam causar dor ou angústia desenvolver-se-ão sob sedação, analgesia ou anestesia adequadas.

$\S 6^{0}$ Experimentos cujo objetivo seja o estudo dos processos relacionados à dor e à angústia exigem autorização específica da CEUA, em obediência a normas estabelecidas pelo CONCEA.

$\S 7^{\mathrm{o}}$ É vedado o uso de bloqueadores neuromusculares ou de relaxantes musculares em substituição a substâncias sedativas, analgésicas ou anestésicas.

$\S 8^{\circ}$ É vedada a reutilização do mesmo animal depois de alcançado o objetivo principal do projeto de pesquisa.

$\S$ 9o Em programa de ensino, sempre que forem empregados procedimentos traumáticos, vários procedimentos poderão ser realizados num mesmo animal, desde que todos sejam executados durante a vigência de um único anestésico e que o animal seja sacrificado antes de recobrar a consciência.

$\S$ 10. Para a realização de trabalhos de criação e experimentação de animais em sistemas fechados, serão consideradas as condições e normas de segurança recomendadas pelos organismos internacionais aos quais o Brasil se vincula."

A norma federal, portanto, possui uma natureza permissiva no que 


\section{ADI 5996 / AM}

diz respeito à utilização de animais em atividades de ensino e pesquisas científicas, desde que sejam observadas algumas condições relacionadas aos procedimentos adotados, que visam a evitar e/ou atenuar o sofrimento dos animais.

No âmbito do Estado do Amazonas, o tema foi abordado de uma maneira mais restrita, pois a assembleia legislativa local editou norma proibindo a utilização de animais para o desenvolvimento, experimentos e testes de produtos cosméticos, de higiene pessoal e de perfumes, inclusive estipulando sanção pecuniária e administrativa no caso de descumprimento da lei.

Assim, cabe examinar se essa proibição invade a competência da União para editar normas gerais sobre a utilização de animais em pesquisas científicas.

A delimitação do que seriam normas gerais em matéria submetida à legislação concorrente, bem como a definição do alcance da competência suplementar, é decisiva para a solução da presente Ação Direta, com base na manutenção do equilíbrio constitucional, pois o federalismo e suas regras de distribuição de competências legislativas são um dos grandes alicerces da consagração da fórmula Estado de Direito, que, conforme salientado por PABLO LUCAS VERDÚ, ainda exerce particular fascinação sobre os juristas. Essa fórmula aponta a necessidade de o Direito ser respeitoso com as interpretações acerca de diferentes dispositivos constitucionais que envolvem diversas competências legislativas, para que se garanta a previsão do legislador constituinte sobre a divisão dos centros de poder entre os entes federativos, cuja importância é ressaltada tanto por JORGE MIRANDA (Manual de direito constitucional. 4. Ed. Coimbra: Coimbra Editora, 1990, t.1, p. 13-14), quanto por JOSÉ GOMES CANOTILHO (Direito constitucional e teoria da Constituição. Almedina, p. 87).

A essencialidade da discussão não está na maior ou menor importância do assunto específico tratado pela legislação, mas sim, na observância respeitosa à competência constitucional do ente federativo para editá-la (MAURICE DUVERGER. Droit constitutionnel et institutions 


\section{ADI 5996 / AM}

politiques. Paris: Presses Universitaires de France, 1955. p. 265 e ss.), com preservação de sua autonomia e sem interferência dos demais entes da federação, pois, como salientado por LÚCIO LEVI:

"a federação constitui, portanto, a realização mais alta dos princípios do constitucionalismo. Com efeito, a ideia do Estado de direito, o Estado que submete todos os poderes à lei constitucional, parece que pode encontrar sua plena realização somente quando, na fase de uma distribuição substancial das competências, o Executivo e o Judiciário assumem as características e as funções que têm no Estado Federal". (NORBERTO BOBBIO, NICOLA MATTEUCCI, GIANFRANCO PASQUINO (Coord.). Dicionário de política. v. I, p. 482).

O equilíbrio na interpretação constitucional sobre a distribuição de competências na história do federalismo iniciou com a Constituição norte-americana de 1787. A análise de suas características e consequências, bem como do desenvolvimento de seus institutos vem sendo realizada desde os escritos de JAY, MADISON e HAMILTON, nos artigos federalistas, publicados sob o codinome Publius, durante os anos de 1787-1788, até os dias de hoje, e mostra que se trata de um sistema baseado principalmente na consagração da divisão constitucional de competências, para manutenção de autonomia dos entes federativos e equilíbrio no exercício do poder (THOMAS MCINTYRE COOLEY. The general principles of constitutional law in the United States of America. 3. ed. Boston: Little, Brown and Company, 1898. p. 52; DONALD L. ROBINSON. To the best of my ability: the presidency the constitution. New York: W. W. Norton \& Company, 1987. p. 18-19). Em 1887, em seu centenário, o estadista inglês WILLIAM GLADSTONE, um dos mais influentes primeiros-ministros ingleses, afirmou que a Constituição dos Estados Unidos "era a mais maravilhosa obra jamais concebida num momento dado pelo cérebro e o propósito do homem", por equilibrar o exercício do poder.

É importante salientar, dentro dessa perspectiva da "mais maravilhosa 


\section{ADI 5996 / AM}

obra jamais concebida", que a questão do federalismo e do equilíbrio entre o Poder Central e os Poderes Regionais foi das questões mais discutidas durante a Convenção norte-americana, pois a manutenção do equilíbrio Democrático e Republicano, no âmbito do Regime Federalista, depende do bom entendimento, definição, fixação de funções, deveres e responsabilidades entre os três Poderes, bem como da fiel observância da distribuição de competências legislativas, administrativas e tributárias entre União, Estados e Municípios, característica do Pacto Federativo, consagrado constitucionalmente no Brasil, desde a primeira Constituição Republicana, em 1891, até a Constituição Federal de 1988.

A Federação, portanto, nasceu adotando a necessidade de um poder central, com competências suficientes para manter a união e coesão do próprio País, garantindo-lhe, como afirmado por HAMILTON, a oportunidade máxima para a consecução da paz e liberdade contra o facciosismo e a insurreição (The Federalist papers, no IX) e permitindo à União realizar seu papel aglutinador dos diversos Estados-Membros e de equilíbrio no exercício das diversas funções constitucionais delegadas aos três poderes de Estado.

Durante a evolução do federalismo, passou-se da ideia de três campos de poder mutuamente exclusivos e limitadores, segundo a qual a União, os Estados e os Municípios teriam suas áreas exclusivas de autoridade, para um novo modelo federal baseado principalmente na cooperação, como salientado por KARL LOEWENSTEIN (Teoria de la constitución. Barcelona: Ariel, 1962. p. 362).

O legislador constituinte de 1988, atento a essa evolução, bem como sabedor da tradição centralizadora brasileira, tanto obviamente nas diversas ditaduras que sofremos, quanto nos momentos de normalidade democrática, instituiu novas regras descentralizadoras na distribuição formal de competências legislativas, com base no princípio da predominância do interesse, e ampliou as hipóteses de competências concorrentes, além de fortalecer o Município como polo gerador de normas de interesse local.

O princípio geral que norteia a repartição de competência entre os 


\section{ADI 5996 / AM}

entes componentes do Estado Federal brasileiro, portanto, é o princípio da predominância do interesse, não apenas para as matérias cuja definição foi preestabelecida pelo texto constitucional, mas também em termos de interpretação em hipóteses que envolvem várias e diversas matérias, como na presente ação direta de inconstitucionalidade.

A própria Constituição Federal, presumindo de forma absoluta para algumas matérias a presença do princípio da predominância do interesse, estabeleceu, a priori, diversas competências para cada um dos entes federativos, União, Estados-Membros, Distrito Federal e Municípios, e, a partir dessas opções, pode ora acentuar maior centralização de poder, principalmente na própria União $(\mathrm{CF}$, art. 22), ora permitir uma maior descentralização nos Estados-Membros e Municípios (CF, arts. 24 e 30, inciso I).

Atuando dessa maneira, se, na distribuição formal de competências, houve um maior afastamento do federalismo centrípeto que sempre caracterizou a república brasileira, na distribuição material, nossas tradições históricas, político-econômicas e culturais, somadas ao próprio interesse do legislador constituinte, que permaneceria como poder constituído (Congresso Nacional), após a edição da Constituição de 1988, acabaram por produzir grande generosidade do texto constitucional na previsão dos poderes enumerados da União, com a fixação de competência privativa para a maioria dos assuntos de maior importância legislativa.

Consequentemente, concordemos ou não, no texto da Constituição de 1988, as contingências históricas, político-econômicas e culturais mantiveram a concentração dos temas mais importantes no Congresso Nacional, em detrimento das Assembleias locais, como salientado por JOSÉ ALFREDO DE OLIVEIRA BARACHO (Teoria geral do federalismo. Rio de Janeiro: Forense, 1986. p. 317), e facilmente constatado ao analisarmos o rol de competências legislativas da União estabelecidas no artigo 22 do texto constitucional.

Essa opção inicial do legislador constituinte, ao centralizar nos poderes enumerados da União $(\mathrm{CF}$, artigo 22) a maioria das matérias 


\section{ADI 5996 / AM}

legislativas mais importantes, contudo, não afastou da Constituição de 1988 os princípios básicos de nossa tradição republicana federalista, que gravita em torno do princípio da autonomia, da participação política e da existência de competências legislativas próprias dos Estados/Distrito Federal e Municípios, indicando ao intérprete a necessidade de aplicá-los como vetores principais em cada hipótese concreta em que haja a necessidade de análise da predominância do interesse, para que se garanta a manutenção, fortalecimento e, principalmente, o equilíbrio federativo (GERALDO ATALIBA. República e constituição. São Paulo: Revista dos Tribunais, 1985. p. 10), que se caracteriza pelo respeito às diversidades locais, como bem salientado por MICHAEL J. MALBIN, ao apontar que a intenção dos elaboradores da Carta Constitucional Americana foi justamente estimular e incentivar a diversidade, transcendendo as facções e trabalhando pelo bem comum ( $A$ ordem constitucional americana. Rio de Janeiro: Forense Universitária, 1987, p. 144), consagrando, ainda, a pluralidade de centros locais de poder, com autonomia de autogoverno e autoadministração, para que se reforçasse a ideia de preservação da autonomia na elaboração do federalismo, como salientado por ALEXIS DE TOCQUEVILLE, ao comentar a formação da nação americana (Democracia na América: leis e costumes. São Paulo: Martins Fontes, 1988. p. 37 e ss.), que serviu de modelo à nossa Primeira Constituição Republicana em 1891.

Nos regimes federalistas, respeitadas as opções realizadas pelo legislador constituinte e previamente estabelecidas no próprio texto constitucional, quando surgem dúvidas sobre a distribuição de competências e, consequentemente, a necessidade de definição do ente federativo competente para legislar sobre determinado e específico assunto, que engloba uma ou várias matérias com previsão ou reflexos em diversos ramos do Direito, caberá ao interprete priorizar o fortalecimento das autonomias locais e o respeito às suas diversidades como pontos caracterizadores e asseguradores do convívio no Estado Federal, que garantam o imprescindível equilíbrio federativo (JUAN FERRANDO BADÍA. El estado unitário: El federal y El estado regional. 


\section{ADI 5996 / AM}

Madri: Tecnos, 1978, p. 77; MANOEL GONÇALVES FERREIRA FILHO.

O Estado federal brasileiro na Constituição de 1988. Revista de Direito Administrativo, n. 179, p. 1; RAUL MACHADO HORTA. Tendências atuais da federação brasileira. Cadernos de direito constitucional e ciência política, n. 16, p. 17; e, do mesmo autor: Estruturação da federação. Revista de Direito Público, n. 81, p. 53 e ss.; CARLOS MÁRIO VELLOSO. Estado federal e estados federados na Constituição brasileira de 1988: do equilíbrio federativo. Revista de Direito Administrativo, n. 187, p. 1 e ss.; JOSAPHAT MARINHO. Rui Barbosa e a federação. Revista de Informação Legislativa, n. 130, p. 40 e ss.; SEABRA FAGUNDES. Novas perspectivas do federalismo brasileiro. Revista de Direito Administrativo, n. 99, p. 1 ess.).

Em matéria de proteção ambiental, especificamente, e aqui entra a defesa da fauna, a opção tomada pelo Constituinte foi a de partilhar competências materiais e legiferantes, como já assinalado acima, com a transcrição do art. 24, VI, da CF.

Assim sendo, nada impõe a necessária prevalência da legislação editada pelo ente central, especialmente quando considerado que a norma estadual veicula disciplina ambiental mais protetiva, se comparado com a lei federal que tratou da mesma matéria.

Em rigor, o Estado do Amazonas, por meio da norma ora impugnada, não proibiu toda e qualquer realização de testes em animais dentro de seu território, tendo apenas escolhido, dentro da sua competência legiferante, proibir a utilização de animais para o desenvolvimento, experimentos e testes de produtos cosméticos, de higiene pessoal e perfumes.

A propósito, merece atenção a colaboração trazida ao debate pela Humane Society International (HSI), na qualidade de amicus curiae, na qual consigna o seguinte (peça 24, fl. 29):

"A crescente proteção aos animais contra testes realizados pela indústria de cosméticos é tendência mundial irreversível do ponto de vista ético, científico e econômico. Globalmente, os testes cosméticos em animais já são proibidos em 37 países, incluindo tanto países desenvolvidos, como os 28 integrantes da 


\section{ADI 5996 / AM}

União Europeia, Israel, Noruega, Suíça, Taiwan e Nova Zelândia, quanto países em desenvolvimento, como são exemplos Índia, Turquia e Guatemala."

Percebe-se, portanto, que o legislador amazonense optou por seguir um movimento mundial no sentido de proibir os experimentos e testes de cosméticos em animais, o que não torna censurável o exercício de sua competência concorrente para tratar do tema, visando à proteção da vida animal. Ressalta-se que outras unidades da Federação também adotaram o mesmo caminho, conforme demonstrado pelo amicus curiae (peça 24, fls. 32-33).

O próprio Conselho Nacional de Controle de Experimentação Animal - CONCEA, criado pela Lei 11.794/2008, já se manifestou da seguinte maneira a respeito do tema, como destacado pela Humane Society International (HSI):

A Europa possui mais de uma década de experiência com o banimento de testes em animais para o desenvolvimento de cosméticos. Cientificamente, as vantagens superam as desvantagens. A substituição de testes em animais por métodos alternativos pode não somente atender a pleitos de natureza ética, mas também potencialmente realizar predições com maior acurácia, com prazos e custos menores que os testes em animais. Esse rol de vantagens, associado a políticas de fomento inteligentes e bem formuladas, produziu grandes avanços científicos no desenvolvimento de métodos alternativos com aplicações em cosméticos, fármacos, produtos de limpeza e agroquímicos.

Dessa forma, a sobreposição de opções políticas por graus variáveis de proteção ambiental constitui circunstância própria do estabelecimento de competência concorrente sobre a matéria. Em linha de princípio, admite-se que os Estados editem normas mais protetivas ao meio ambiente, com fundamento em suas peculiaridades regionais e na preponderância de seu interesse, conforme o caso. Nesse sentido, o 


\section{ADI 5996 / AM}

precedente firmado na ADI 3.937-MC (Rel. Min. MARCO AURÉLIO, Tribunal Pleno, DJ de 10/10/2008), que tratou de lei estadual paulista que proibiu a produção e circulação do amianto, confrontada com legislação federal que admite o emprego dessa substância; e o julgamento do RE 194.704 (Rel. para acórdão Min. EDSON FACHIN, Tribunal Pleno, julgamento concluído em 29/6/2017), em que validada lei do Município de Belo Horizonte/MG que estabelecera padrões mais restritos de emissão de gases poluentes.

Diante do exposto, JULGO IMPROCEDENTE a presente Ação Direta de Inconstitucionalidade.

É o voto. 


\section{PLENÁRIO}

\section{EXTRATO DE ATA}

\section{AÇÃO DIRETA DE INCONSTITUCIONALIDADE 5.996}

PROCED. : AMAZONAS

RELATOR : MIN. ALEXANDRE DE MORAES

REQTE. (S) : ASSOC BRASIL DA IND HIGIENE PESSOAL PERF E COSMETICOS ADV. (A/S) : HELOISA BARROSO UELZE BLOISI (221210/RJ, 117088/SP) E $\operatorname{OUTRO}(A / S)$

INTDO. (A/S) : MESA DIRETORA DA ASSEMBLEIA LEGISLATIVA DO ESTADO DO AMAZONAS

ADV. (A/S) : SEM REPRESENTAÇÃO NOS AUTOS

AM. CURIAE. : HUMANE SOCIETY INTERNATIONAL - HSI

ADV. $(A / S)$ : GUSTAVO TEIXEIRA RAMOS (17725/DF)

ADV. $(\mathrm{A} / \mathrm{S})$ : MARIANA PRANDINI FRAGA ASSIS $(52017 / \mathrm{DF})$

Decisão: O Tribunal, por unanimidade, julgou improcedente o pedido formulado na ação direta, nos termos do voto do Relator. Falaram: pela requerente, o Dr. Bruno Corrêa Burini, e, pelo amicus curiae, o Dr. Gustavo Teixeira Ramos. Não participou deste julgamento, por motivo de licença médica no início da sessão, o Ministro Celso de Mello (art. 20, $\$ 5^{\circ}$, da Res. 642/2019). Plenário, Sessão Virtual de 3.4.2020 a 14.4.2020.

Composição: Ministros Dias Toffoli (Presidente), Celso de Mello, Marco Aurélio, Gilmar Mendes, Ricardo Lewandowski, Cármen Lúcia, Luiz Fux, Rosa Weber, Roberto Barroso, Edson Fachin e Alexandre de Moraes.

Carmen Lilian Oliveira de Souza Assessora-Chefe do Plenário 